\title{
Analyses of wrky18 wrky40 Plants Reveal Critical Roles of SA/EDS1 Signaling and Indole-Glucosinolate Biosynthesis for Golovinomyces orontii Resistance and a Loss-of Resistance Towards Pseudomonas syringae pv. tomato AvrRPS4
}

\author{
Moritz Schön, ${ }^{1}$ Armin Töller, ${ }^{1}$ Celia Diezel, ${ }^{2}$ Charlotte Roth, ${ }^{3}$ Lore Westphal, ${ }^{4}$ Marcel Wiermer, ${ }^{3}$ and \\ Imre E. Somssich ${ }^{1}$ \\ ${ }^{1}$ Department of Plant Microbe Interaction, Max Planck Institute for Plant Breeding Research, Carl-von-Linné-Weg 10, 50829 \\ Cologne, Germany; ${ }^{2}$ Department of Molecular Ecology, Max Planck Institute for Chemical Ecology, Hans-Knöll-Straße 8, \\ 07745 Jena, Germany; ${ }^{3}$ Department of Plant Cell Biology, University of Göttingen, Julia-Lermontowa-Weg 3, 37077 \\ Göttingen, Germany; ${ }^{4}$ Leibnitz Institute of Plant Biochemistry, Weinberg 3, 06120 Halle (Saale), Germany
}

Submitted 16 November 2012. Accepted 29 March 2013.

\begin{abstract}
Simultaneous mutation of two WRKY-type transcription factors, WRKY18 and WRKY40, renders otherwise susceptible wild-type Arabidopsis plants resistant towards the biotrophic powdery mildew fungus Golovinomyces orontii. Resistance in wrky18 wrky40 double mutant plants is accompanied by massive transcriptional reprogramming, imbalance in salicylic acid (SA) and jasmonic acid (JA) signaling, altered ENHANCED DISEASE SUSCEPTIBILITY1 (EDS1) expression, and accumulation of the phytoalexin camalexin. Genetic analyses identified SA biosynthesis and EDS1 signaling as well as biosynthesis of the indole-glucosinolate $4 \mathrm{MI} 3 \mathrm{G}$ as essential components required for lossof-WRKY18 WRKY40-mediated resistance towards $G$. orontii. The analysis of wrky 18 wrky 40 pad3 mutant plants impaired in camalexin biosynthesis revealed an uncoupling of pre- from postinvasive resistance against $G$. orontii. Comprehensive infection studies demonstrated the specificity of wrky18 wrky40-mediated $G$. orontii resistance. Interestingly, WRKY18 and WRKY40 act as positive regulators in effector-triggered immunity, as the wrky18 wrky40 double mutant was found to be strongly susceptible towards the bacterial pathogen Pseudomonas syringae DC3000 expressing the effector AvrRPS4 but not against other tested Pseudomonas strains. We hypothesize that $G$. orontii depends on the function of WRKY18 and WRKY40 to successfully infect Arabidopsis wild-type plants while, in the interaction with $P$. syringae AvrRPS4, they are required to mediate effector-triggered immunity.
\end{abstract}

The plant immune system can be subdivided into two main branches, both depending on the perception of nonself or modified-self structures (Maekawa et al. 2011). The first active layer

Corresponding author: I. E. Somssich; E-mail: somssich@mpipz.mpg.de

* The $\boldsymbol{e}$-Xtra logo stands for "electronic extra" and indicates that two supplementary figures are published online and that Figures 1 through 4 appear in color online.

(C) 2013 The American Phytopathological Society of plant defense is based on nonself recognition by detecting molecular components that are structurally conserved across a wide range of microbes but that are normally not present in the host (Chisholm et al. 2006; Dodds and Rathjen 2010). Extracellular perception of these slow-evolving microbe-associated molecular patterns (MAMPs) by pattern recognition receptors triggers downstream cell-autonomous responses leading to MAMP-triggered immunity (MTI). Although effective against most pathogenic threats, MAMP-induced defense responses are insufficient against virulent pathogens. Those pathogens have evolved the ability to evade MTI by secreting specific effector molecules into plant cells that suppress or interfere with MAMP-triggered immune responses. As a consequence, plants have acquired intracellular immune sensors that recognize isolate-specific pathogen effectors. Perception of an effector by an intracellular resistance $(\mathrm{R})$ protein leads to the activation of downstream responses culminating in effector triggered immunity (ETI). Well studied are two signaling branches of ETI activated by Toll-interleukin-like receptor (TIR) or coiledcoil (CC) types of nucleotide binding-leucine-rich repeat (NBLRR) proteins, which require the lipase-like ENHANCED DISEASE SUSCEPTIBILITY 1 (EDS1) or NON-RACE SPECIFIC DISEASE RESISTANCE 1 (NDR1) proteins for effective defense activation, respectively. Whereas resistance induced upon infection with the avirulent bacterial strain Pseudomonas syringae pv. tomato expressing the effector AvrRPS4 is EDS1dependent, effective defense against $P$. syringae pv. tomato AvrRPM1 requires NDR1 (Aarts et al. 1998; Falk et al. 1999; Moreau et al. 2012).

Both, MTI and ETI involve similar downstream events comprising transcriptional reprogramming, the activation of defense hormone pathways, and the production of (antimicrobial) secondary metabolites. Two major plant defense hormones are jasmonic acid (JA) and salicylic acid (SA). In general, JA signaling is associated with defense against necrotrophic pathogens, whereas SA plays essential roles against biotrophic pathogens (Glazebrook 2005). Moreover, EDS1 was shown to be a core component of both MTI and ETI with edsl mutants revealing defects in basal defense but also in defense responses mediated via TIR-NB-LRR R proteins (Heidrich et al. 2011; Parker et al. 1996; Wiermer et al. 2005). 
In barley, the CC-NB-LRR R protein MILDEW LOCUS A10 (MLA10) mediates effector-triggered resistance towards the obligate biotrophic powdery mildew fungus Blumeria graminis f. sp. hordei. This resistance necessitates effector-dependent association of MLA10 with the transcriptional repressors WRKY1 and WRKY2 in the nucleus (Shen et al. 2007). In Arabidopsis, transcription of the barley homologs WRKY18 and WRKY40 is rapidly activated in response to the host-adapted powdery mildew fungus Golovinomyces orontii (Pandey et al. 2010). Whereas wrkyl8 wrky40 double mutant plants are resistant against $G$. orontii, wild-type plants are susceptible, with strong fungal sporulation observed on infected leaf surfaces at 7 days postinfection (dpi) (Eichmann and Huckelhoven 2008; Shen et al. 2007). During the last decade, numerous powdery mildew-resistant mutants have been identified in forward genetic screens (Frye and Innes 1998; Vogel and Somerville 2000). Many of these exhibit broad-spectrum resistances or reveal constitutive defense activation (Ellis and Turner 2001; Ellis et al. 2002; Nishimura et al. 2003; Vogel and Somerville 2000; Vogel et al. 2002, 2004). Identified components of defense execution include the syntaxin PENETRATION1 (PEN1), the atypical myrosinase PEN2, and the ABC transporter PEN3 (Bednarek et al. 2009; Collins et al. 2003; Stein et al. 2006). The PEN2-dependent breakdown of the antimicrobial tryptophan (Trp)-derived indole-glucosinolate methoxyindol-3-ylmethylglucosinolate $(4 \mathrm{MI} 3 \mathrm{G})$ was recently implicated in resistance towards a variety of fungal pathogens and its sequential action with camalexin, the major Arabidopsis phytoalexin, in restricting nonhost powdery mildew infection (Bednarek et al. 2009; Schlaeppi and Mauch 2010; Schlaeppi et al. 2010).

We previously demonstrated that lack of WRKY18 and WRKY4O results in a massive transcriptional reprogramming during early stages of $G$. orontii infection (Pandey et al. 2010). Expression of several positive and negative regulators of JA and SA signaling and crucial biosynthesis genes of Trpderived antimicrobial compounds was significantly altered in resistant wrky 18 wrky40 compared with susceptible wild-type plants. In addition, camalexin was found to accumulate to high levels upon infection in wrky 18 wrky 40 plants.

In this study, we provide genetic evidence that preinvasive fungal entry restriction in wrky 18 wrky 40 depends on the production of the Trp-derived antimicrobial compounds camalexin

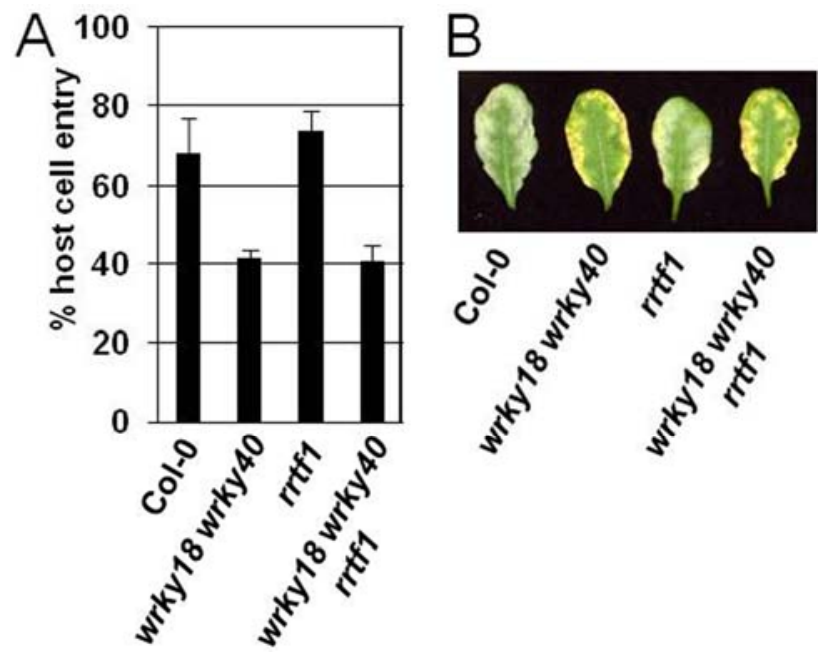

Fig. 1. RRTF 1 is dispensable for resistance of wrky 18 wrky 40 plants towards Golovinomyces orontii. A, Host cell-entry rates of fungal spores determined $48 \mathrm{~h}$ postinoculation and $\mathbf{B}$, phenotypic characterization of homozygous rrtfl single, wrky 18 wrky 40 double, and wrky 18 wrky 40 rrtfl triple mutant plants at 9 days after infection with $G$. orontii. Values in A represent means \pm standard deviation. $n=4$. and the indole-glucosinolate $4 \mathrm{MI} 3 \mathrm{G}$ or its breakdown products. Moreover, we found late disease resistance independent of early host cell-entry restriction and wrky 18 wrky 40 resistance towards $G$. orontii independent of the PEN1 secretion pathway. Furthermore, we demonstrate that loss-of-WRKY18 WRKY40dependent pre- and postinvasive $G$. orontii resistance depends on the SA/EDS1 signaling pathway. Finally, we discovered that wrky 18 wrky 40 mutant plants do not exhibit a broad-spectrum resistance towards powdery mildew fungi but reveal increased susceptibility specifically towards $P$. syringae pv. tomato AvrRPS4. Thus, WRKY18 and WRKY40 negatively regulate resistance against $G$. orontii but positively influence resistance against $P$. syringae pv. tomato AvrRPS4.

\section{RESULTS}

wrky18 wrky40 resistance against $G$. orontii is independent of preinvasive host cell-entry restriction.

In our previous study, the ERF/AP2-type redox-responsive transcription factor 1 (RRTF1; Khandelwal et al. 2008) displayed 12-fold higher basal transcript levels in wrky18 wrky40 compared with wild-type plants, and binding of WRKY40 protein to the RRTF1 promoter was demonstrated in planta (Pandey et al. 2010). To test its putative contribution to the G. orontii resistance phenotype, we generated homozygous wrkyl8 wrky40 rrtfl triple mutant plants. We first determined the ratio of spores showing secondary hyphae formation to all spores that formed an appressorium $48 \mathrm{~h}$ postinfection (hpi), indicative of successful host cell entry by the pathogen (Fig. 1A). While $r r t f l$ single mutants showed wild-type-like fungal entry rates of about $70 \%$, wrky 18 wrky 40 rrtfl triple mutants displayed a reduction in host cell entry to about $40 \%$. However, this reduction was indistinguishable from resistant wrkyl8 wrky40 double mutant plants. At later infection stages (9 dpi), loss of RRTF1 did not alter the resistant phenotype of wrky 18 wrky 40 plants characterized by the absence of macroscopically visible fungal sporulation on the leaf surface (Fig. 1B). Together these data suggest RRTF1 function to be redundant or dispensable for wrky 18 wrky 40 resistance towards $G$. orontii.

We previously reported rapid and significant accumulation of the antifungal secondary metabolite camalexin and strong

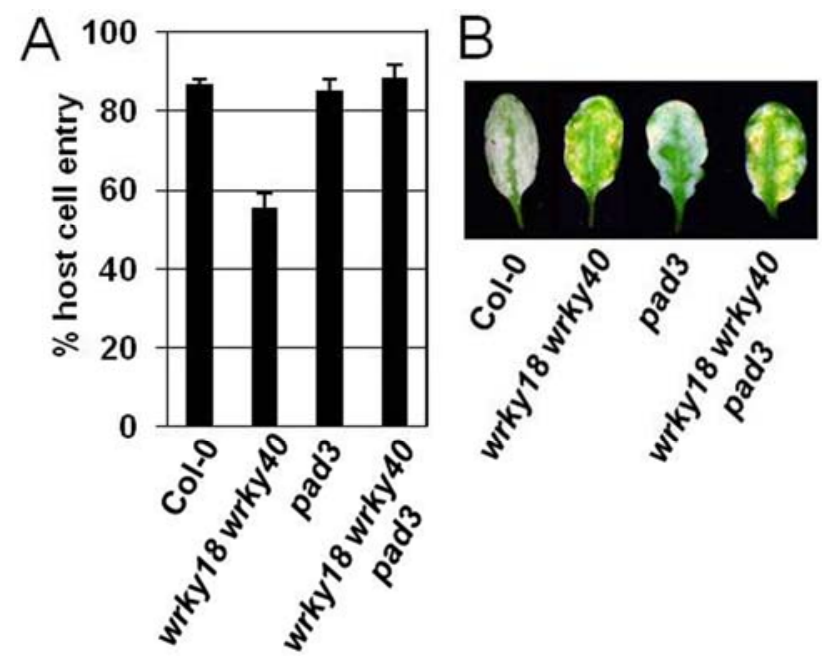

Fig. 2. $P A D 3$ is required for preinvasive but not for postinvasive resistance in wrky 18 wrky 40 plants. A, Host cell-entry rates of fungal spores determined at $48 \mathrm{~h}$ postinoculation and $\mathbf{B}$, phenotypic characterization of pad3 single, wrky 18 wrky 40 double, and wrky18 wrky40 pad3 triple mutant plants at 9 days after infection with Golovinomyces orontii. Values in A represent means \pm standard deviation. $n=4$. 
induction of the crucial biosynthesis genes $C Y P 71 A 13$ and PHYTOALEXIN-DEFICIENT3 (PAD3, CYP71B15) in resistant wrky 18 wrky 40 double mutant plants within $24 \mathrm{~h}$ after $G$. orontii infection (Pandey et al. 2010). To test whether camalexin is an essential component of resistance in wrky18 wrky 40 plants, we generated a camalexin-deficient wrkyl8 wrky40 mutant lacking the key camalexin biosynthesis gene PAD3. Homozygous wrky 18 wrky 40 pad3 plants were infected with $G$. orontii and were examined for successful fungal host cell entry at 48 hpi. Camalexin-deficient pad3 single mutants revealed wild-type-like fungal entry rates, whereas wrky 18 wrky 40 plants showed reduced penetration rates, as expected. Indeed, knockdown of camalexin biosynthesis in the wrky 18 wrky 40 double mutant background resulted in the reconstitution of wild-type-like fungal entry rates up to $90 \%$ (Fig. 2A), indicating that rapid elevation of camalexin levels in response to $G$. orontii infection in resistant wrky 18 wrky 40 plants is required for early fungal host cell-entry restriction. Interestingly, however, at later infection stages, wrky 18 wrky 40 pad3 triple mutants displayed a wrky 18 wrky 40 -like resistant phenotype, characterized by macroscopically undetectable fungal sporulation and formation of necrotic lesions on infected leaf surfaces (Fig. 2B). In contrast, pad3 single mutants exhibited susceptibility with wild-type-like $G$. orontii sporulation. These data demonstrate an essential role of PAD3 for preinvasive fungal host cell-entry restriction but not for later postinvasive defense against $G$. orontii in the wrky 18 wrky 40 double mutant.
4MI3G biosynthesis is indispensable

for pre- and postinvasive resistance of wrky18 wrky 40 .

Previous reports describe the sequential action of camalexin and the PEN2-dependent turnover of 4MI3G in Arabidopsis nonhost resistance (Bednarek et al. 2009; Schlaeppi et al. 2010). Another independent secretion pathway is represented by the plasma membrane (PM)-resident syntaxin PEN1, which together with soluble adaptor protein SNAP33 and vesicleassociated membrane protein VAMP721/VAMP722 forms PMlocalized ternary SNARE complexes required for penetration resistance towards nonadapted powdery mildews (Collins et al. 2003; Kwon et al. 2008). To analyze putative contributions of these pathways to wrkyl8 wrky40-dependent $G$. orontii resistance, we attempted to generate the respective triple mutants. Since we failed to identify a homozygous wrky 18 wrky 40 pen 2 mutant, we generated triple mutants impaired in $4 \mathrm{MI} 3 \mathrm{G}$ biosynthesis and the PEN1 secretion pathway by mutations in $C Y P 81 F 2$ and PEN1, respectively. Fungal entry rates of $w r k y 18$ wrky40 pen 1 triple mutants did not differ from wrkyl8 wrky 40 double mutant plants (Fig. 3A). However, at later infection stages, resistance in wrkyl8 wrky 40 penl plants was associated with the appearance of large brownish necrotic leaf areas that were absent in resistant wrky18 wrky40 plants (Fig. 3B). In contrast, wild-type-like penetration rates and a susceptible phenotype were reconstituted in wrky 18 wrky 40 cyp $81 f 2$ triple mutants, indicating a crucial role of $4 \mathrm{MI} 3 \mathrm{G}$ for both pre- and postinvasive $G$. orontii resistance in wrkyl8 wrky40 plants (Fig. $3 \mathrm{~A}$ and $\mathrm{B})$. Detailed expression kinetic studies by quantitative
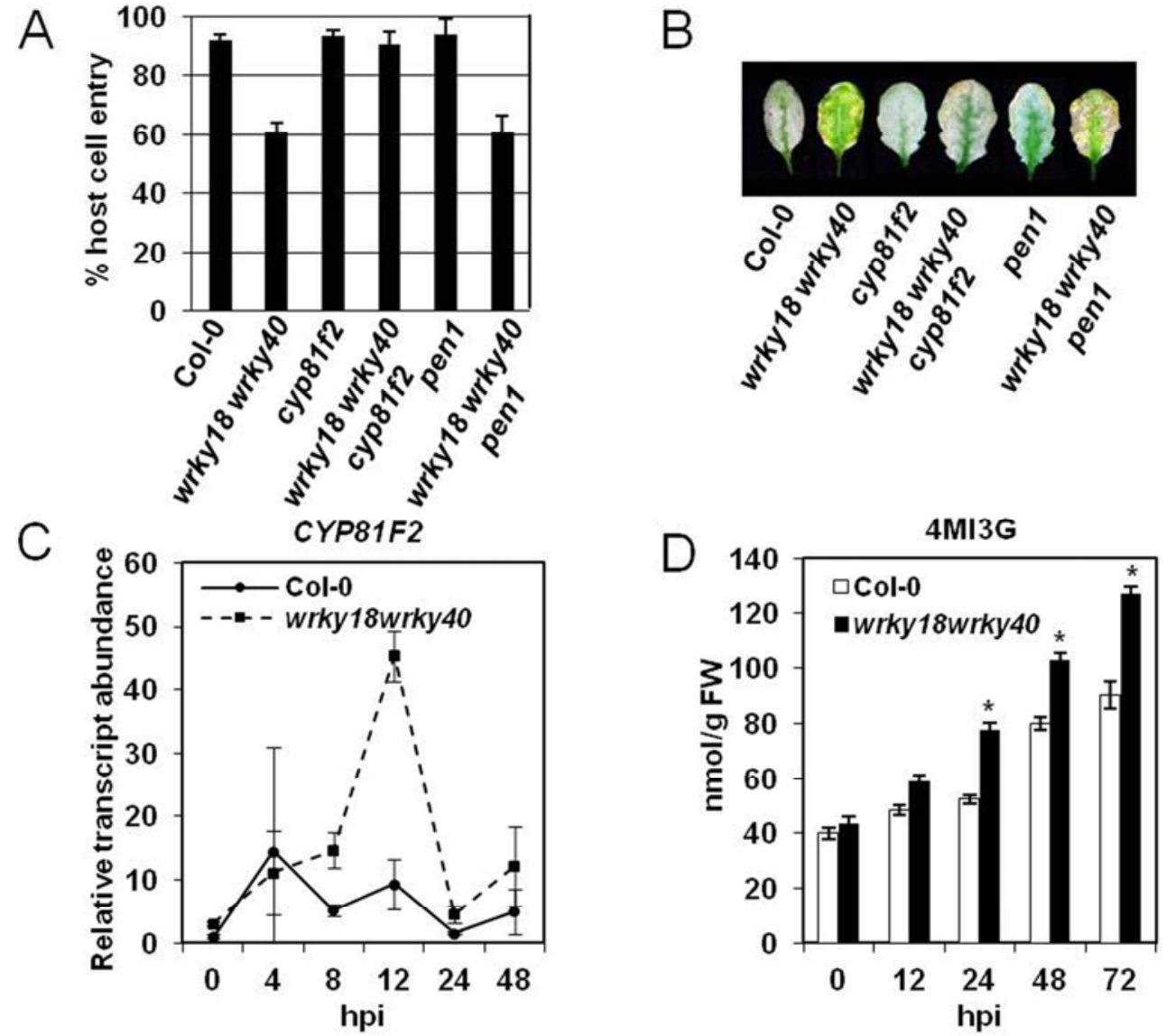

Fig. 3. $4 \mathrm{MI} 3 \mathrm{G}$ accumulates more strongly in wrky 18 wrky 40 plants and is required for the $w r k y 18$ wrky 40 resistance phenotype. A, Host cell-entry rates of fungal spores determined $48 \mathrm{~h}$ postinoculation and B, phenotypic characterization of wrky 18 wrky 40 cyp 81 f2 and wrky 18 wrky 40 pen 1 triple mutant plants and additional indicated genotypes at 9 days postinoculation with Golovinomyces orontii. C, Temporal expression analysis of $4 \mathrm{MI} 3 \mathrm{G}$ biosynthesis gene CYP81F2 during G. orontii infection in susceptible wild-type Col-0 (solid line) and resistant wrky 18 wrky 40 plants (dashed line) and D, $4 \mathrm{MI} 3 \mathrm{G}$ accumulation in Col-0 (white bars) and wrky 18 wrky 40 plants (black bars) during the first $72 \mathrm{~h}$ after $G$. orontii infection. Values represent means \pm standard deviation. $n=4(\mathrm{~A}$ and D), and $2(\mathrm{C})$. Asterisks $(*)$ indicate a $P$ value $<0.01$ compared with wild-type samples at the same time point based on Student's $t$-test. 
reverse transcription polymerase chain reaction (qRT-PCR) confirmed and extended previous microarray studies showing that the crucial $4 \mathrm{MI} 3 \mathrm{G}$ biosynthesis gene $C Y P 81 F 2$ is strongly induced in the resistant double mutant upon $G$. orontii infection, with infected wild-type plants showing similar expression kinetics but with strongly reduced transcript levels (Fig. 3C). To test whether induced expression of the biosynthesis gene correlates with the production of the respective compound, 4MI3G measurements were performed in the course of $G$. orontii infection. Indeed, from $24 \mathrm{~h}$ onwards, resistant wrky 18 wrky 40 plants accumulated significantly more $4 \mathrm{MI} 3 \mathrm{G}$ upon $G$. orontii infection as compared with wild-type plants (Fig. 3D). At 72 hpi, wrkyl8 wrky 40 plants accumulate approximately $25 \%$ more $4 \mathrm{MI} 3 \mathrm{G}$ than susceptible wild-type plants. Together, these data indicate that wrky18 wrky40 resistance towards $G$. orontii is independent of PEN1 but requires CYP81F2 function for pre- and postinvasive fungal growth restriction.

\section{EDS1 and SA are required}

for $G$. orontii resistance by wrky 18 wrky 40 plants.

In vivo binding of WRKY40 to the EDS1 promoter and altered EDS1 transcript levels in wrky 18 wrky 40 mutant plants upon infection provided hints that this central component of the plant immune system may be a vital contributor to resistance towards G. orontii (Pandey et al. 2010). EDS1 contributes to postinvasive nonhost resistance as well as to SA-dependent and SA-independent defense signaling in incompatible host pathogen interactions (Bartsch et al. 2006; Lipka et al. 2008; Wiermer et al. 2005). Moreover, SA-dependent defense responses acting downstream of EDS1 have been demonstrated to be induced upon G. orontii infection (Dewdney et al. 2000; Reuber et al. 1998). To estimate one or more EDS1 and SA contributions to wrkyl8 wrky40 resistance, we first measured
SA levels in wrkyl8 wrky40 and wild-type plants during $G$. orontii infection. SA levels increased 24 hpi in wild-type and wrky 18 wrky 40 plants and peaked 48 hpi with fourfold higher SA levels detected as compared with basal amounts (Fig. 4A). However, no variation in timing and magnitude of basal and induced SA levels were detected between the two genotypes

Table 1. Powdery mildew resistance or susceptibility in wrky 18 wrky 40 mutant plants ${ }^{\mathrm{a}}$

\begin{tabular}{|c|c|c|}
\hline Pathogen & Col-0 & wrky18 wrky 40 \\
\hline Golovinomyces orontii $^{\text {b }}$ & $\mathrm{S}$ & $\mathrm{R}$ \\
\hline Golovinomyces cichoracearum $^{\mathrm{b}}$ & $\mathrm{S}$ & $\mathrm{S}$ \\
\hline Golovinomyces cruciferarum ${ }^{\mathrm{b}}$ & S & S \\
\hline Botrytis cinerea $^{\mathrm{c}}$ & $\mathrm{R}$ & $\mathrm{R}$ \\
\hline Phytophthora infestans ${ }^{\mathrm{d}}$ & $\mathrm{R}$ & $\mathrm{R}$ \\
\hline Hyaloperonospora arabidopsidis $\mathrm{Emco}^{\mathrm{e}}$ & $\mathrm{S}$ & $\mathrm{S}$ \\
\hline H. arabidopsidis $\mathrm{Emwa}^{\mathrm{e}}$ & $\mathrm{R}$ & $\mathrm{R}$ \\
\hline H. arabidopsidis $\mathrm{Cala2} 2^{\mathrm{e}}$ & $\mathrm{R}$ & $\mathrm{R}$ \\
\hline Pseudomonas syringae pv. tomato $\mathrm{DC} 3000^{\mathrm{f}}$ & $\mathrm{S}$ & $\mathrm{S}$ \\
\hline P. syringae pv. tomato DC3000 AvrRPM1 ${ }^{\mathrm{f}}$ & $\mathrm{R}$ & $\mathrm{R}$ \\
\hline P. syringae pv. tomato $\mathrm{DC} 3000 \mathrm{HopA}^{\mathrm{f}}$ & $\mathrm{R}$ & $\mathrm{R}$ \\
\hline P. syringae pv. tomato DC3000 AvrRPS4 ${ }^{\mathrm{f}}$ & $\mathrm{R}$ & $\mathrm{S}$ \\
\hline
\end{tabular}

${ }^{a}$ Four-week-old plants were infected with the indicated pathogens. Macroscopic characterization of infection phenotypes was performed for all pathogens. All infections were repeated at least twice with similar results. $\mathrm{S}=$ susceptible, $\mathrm{R}=$ resistant.

${ }^{\mathrm{b}}$ Microscopically determined by comparing host cell-entry rates to conidi ophore counts

${ }^{c}$ Plant leaves were inoculated by droplet-infection and leaf lesion sizes were macroscopically compared.

${ }^{\mathrm{d}}$ Susceptibility was determined by trypan blue staining of droplet-infected leaves.

e 10-day-old seedlings were spray-infected and susceptibility was determined by trypan blue staining.

${ }^{\mathrm{f}}$ Analyzed by bacterial colony counts after spray infections.
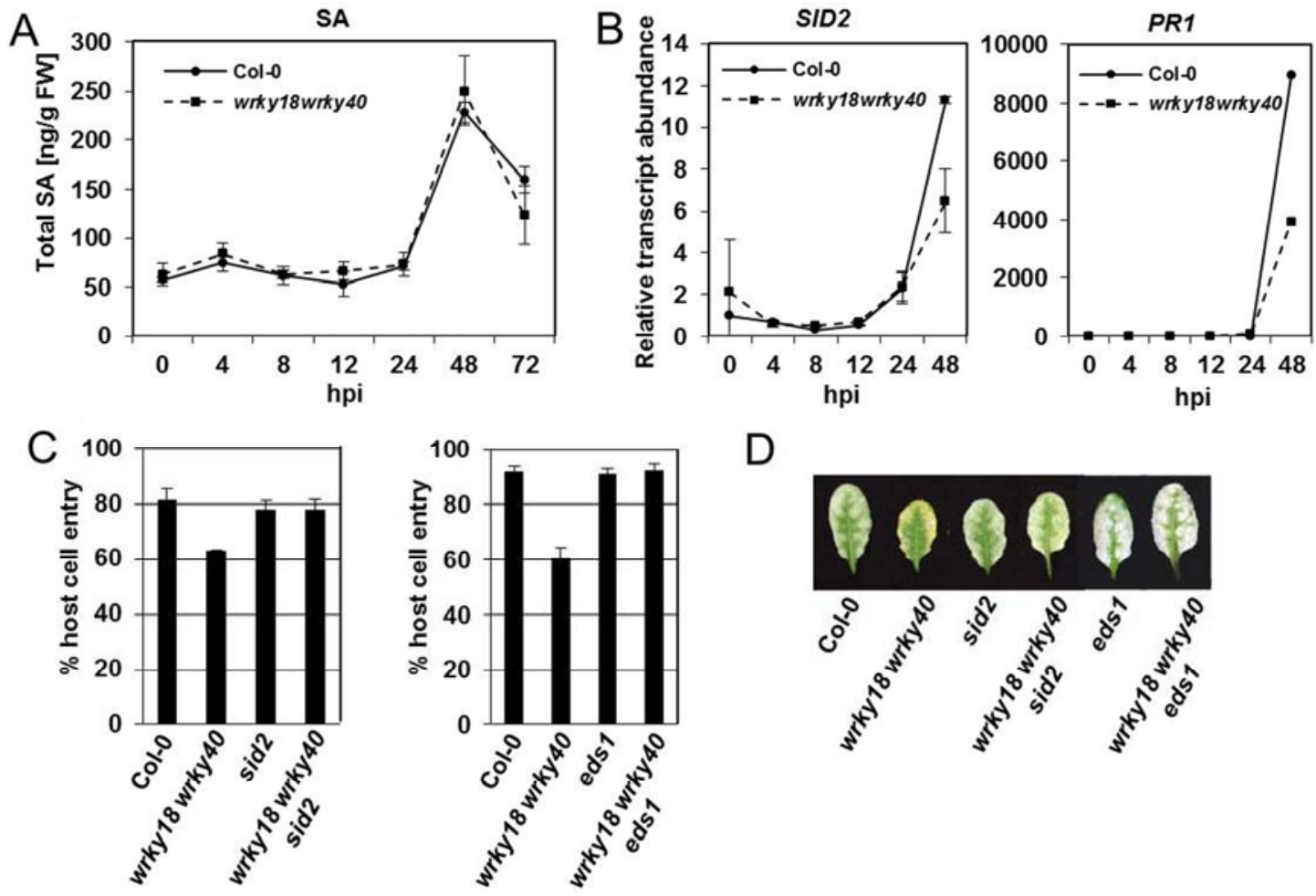

D

Fig. 4. Susceptible wild-type and resistant wrky 18 wrky40 plants accumulate similar levels of salicylic acid (SA) during Golovinomyces orontii infection but SA and EDS1 signaling is indispensable for resistance of wrky 18 wrky 40 plants against G. orontii. A, SA levels during the first $72 \mathrm{~h}$ after $G$. orontii infection in wild-type Col-0 (solid line) and wrky 18 wrky 40 plants (dashed line). B, Temporal expression of SA biosynthesis gene SID2 and SA downstream marker gene $P R 1$ during the first $48 \mathrm{~h}$ after $G$. orontii infection in wild-type Col-0 (solid line) and wrky18 wrky 40 plants (dashed line). C, Host cell-entry rates of fungal spores at $48 \mathrm{~h}$ postinoculation and $\mathbf{D}$, phenotypic characterization of sidl, eds 1 , wrky 18 wrky 40 , wrky 18 wrky 40 sid2, and wrky 18 wrky 40 eds 1 mutant plants at 9 days after infection with G. orontii. Values represent means \pm standard deviation. $n=4$ (A), 2 (B), or 4 (C). 
during the course of $G$. orontii infection. This data correlates with an invariant transcriptional activation of the SA biosynthesis gene SID2/ICS1 in both genotypes in response to $G$. orontii infection (Fig. 4B). Next, we measured induction of the downstream marker gene of SA signaling PATHOGENESIS RELATEDI (PRl) (Fig. 4B). Both genotypes showed a clear induction of $P R I$ transcript at $48 \mathrm{hpi}$. Thus, altered EDS1 transcription and loss of WRKY18 and WRKY40 function in $G$. orontii resistant had no direct detectable effect on SA levels and induction of SA-dependent downstream signaling. Despite these findings, additional SA- and EDS1-dependent processes may still be altered in wrky 18 wrky 40 plants as compared with wild-type plants. Alternatively, SA and EDS1 may act upstream of WRKY18 and WRKY40 and, hence, contribute to G. orontii resistance in wrkyl8 wrky 40 plants. To test this, we generated wrky 18 wrky 40 eds 1 and wrky 18 wrky40 sid2 triple mutants, respectively. As described above, susceptible wild-type plants displayed fungal entry rates of around $90 \%$ and similar ratios were observed for eds 1 and sid2 single mutants (Fig. 4C). In contrast, fungal entry rates were significantly reduced to $65 \%$ in the wrky 18 wrky 40 double mutant. However, loss of EDS1 or SID2 in the wrky 18 wrky 40 background restored fungal entry rates to wild-type-like levels (Fig. 4C), demonstrating that wrky 18 wrky 40 -dependent enhanced preinvasive resistance towards $G$. orontii depends on functional EDS1 and SID2. At later infection stages, wrky 18 wrky 40 sid 2 and wrky 18 wrky 40 eds 1 triple mutant plants exhibited a wild-type-like susceptible phe- notype (Fig. 4D). These findings demonstrate that, although $G$. orontii-induced SA levels do not differ between resistant wrky 18 wrky 40 and susceptible wild-type plants, both SA and EDS1 are required for pre- and postinvasive defense against $G$. orontii in wrky 18 wrky 40 plants.

\section{wrky18 wrky40 mutant plants}

do not exhibit broad-spectrum resistance.

Accumulation of antimicrobial secondary metabolites and $G$. orontii-induced activation of major defense pathways in wrky18 wrky40 plants may suggest a broad-spectrum resistance against powdery mildews, as was reported for other mutant plants (Consonni et al. 2006; Ellis et al. 2002; Nishimura et al. 2003; Vogel and Somerville 2000). Therefore, we investigated the virulence of two additional Arabidopsis-colonizing powdery mildew species, G. cichoracearum and G. cruciferarum, on the wrky 18 wrky 40 double mutant. However, in macroscopic analyses, wrky 18 wrky 40 plants appeared as susceptible as wild-type plants towards both powdery mildew fungi (Table 1). This was verified by wild-type-like conidia formation on wrkyl8 wrky40 plants (Supplementary Fig. 1). Thus, wrky 18 wrky40 plants do not exhibit a broad-spectrum resistance against powdery mildews.

Generally, WRKY18 and WRKY40 are thought to act as repressors of basal defense (Shen et al. 2007). It remains unclear, however, whether both WRKY factors generally antagonize basal resistance against a broad spectrum of invading microbes

Table 2. List of pathogens used in this paper

\begin{tabular}{ll}
\hline Name & Provided by \\
\hline Golovinomyces orontii & V. Lipka, Georg-August-University, Göttingen. Germany \\
G. cichoracearum & V. Lipka, Georg-August-University, Göttingen. Germany \\
G. cruciferarum & V. Lipka, Georg-August-University, Göttingen. Germany \\
Pseudomonas syringae pv. tomato DC3000 & R. Innes, Indiana University, Bloomington, Indiana, U.S.A. \\
P. syringae pv. tomato DC3000 AvrRPS4 & K. Heidrich, Max-Planck Institute for Plant Breeding Research, Cologne, Germany \\
P. syringae pv. tomato DC3000 AvrRPM1 & K. Heidrich, Max-Planck Institute for Plant Breeding Research, Cologne, Germany \\
P. syringae pv. tomato DC3000 HopA1 & K. Heidrich, Max-Planck Institute for Plant Breeding Research, Cologne, Germany \\
Hyaloperonospora arabidopsidis Emco5 & J. Parker, Max-Planck Institute for Plant Breeding Research, Cologne, Germany \\
H. arabidopsidis Emwa1 & J. Parker, Max-Planck Institute for Plant Breeding Research, Cologne, Germany \\
H. arabidopsidis Cala2 & J. Parker, Max-Planck Institute for Plant Breeding Research, Cologne, Germany \\
Phytophtora infestans & D. Scheel, Leibnitz Institute for Plant Biochemistry, Halle Germany \\
Botrytis cinerea (isolate 2100) & R.Birkenbihl, Max-Planck Institute for Plant Breeding Research, Cologne, Germany \\
& Spanish Type Culture, Collection Universidad de Valencia, Burjassot, Spain \\
\hline
\end{tabular}

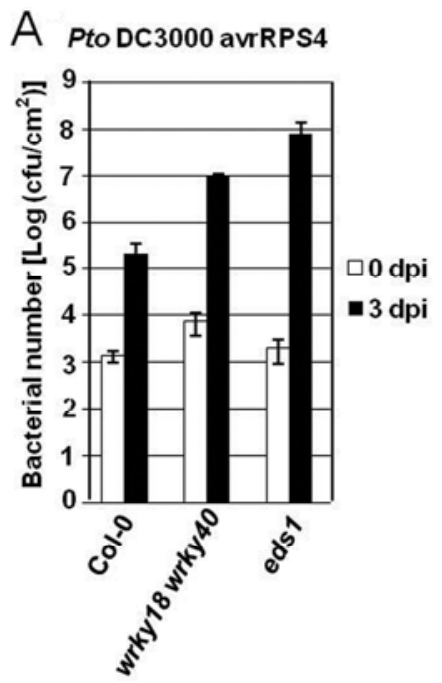

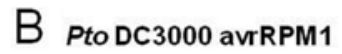

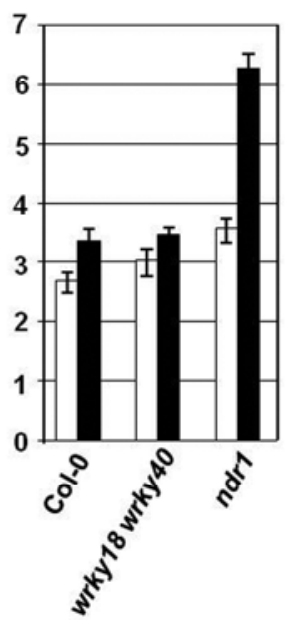

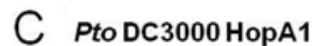

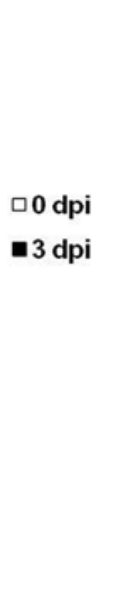

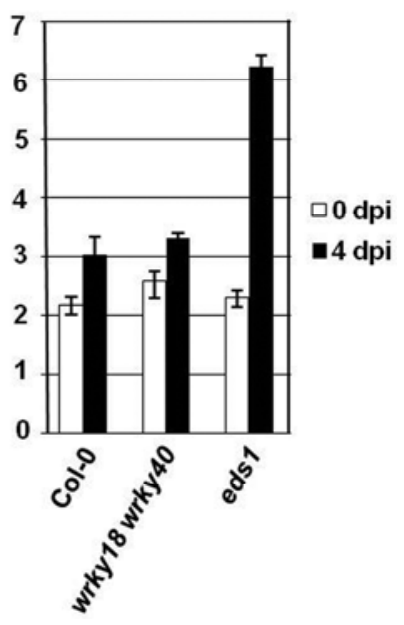

Fig. 5. Increased susceptibility of wrky 18 wrky 40 plants towards Pseudomonas syringae pv. tomato AvrRPS4 infection. Four-week-old wild-type and wrky 18 wrky 40 plants were spray-infected with the bacterial strains $P$. syringae pv. tomato AvrRPS4, P. syringae pv. tomato AvrRPM1, and $P$. syringae pv. tomato HopA1. Bacterial counts were performed A, at 3 days after $P$. syringae pv. tomato AvrRPS4 and $\mathbf{B}, P$. syringae pv. tomato AvrRPM1 and $\mathbf{C}$, at 4 days after $P$. syringae pv. tomato HopA1 infection. The eds 1 and $n d r l$ single mutant plants were included as susceptible controls. Values represent means \pm standard deviation $(n=4)$. The experiments were repeated three times with similar results. 
or whether they modulate the complex interplay of rather specific processes favorable for colonization of a few but inappropriate for other pathogenic intruders. We therefore tested the wrky 18 wrky 40 mutant for resistance or increased susceptibility against distinct pathogens and compared these infection phenotypes with those of wild-type plants after challenge (Table 2). First we infected wild-type and wrky 18 wrky 40 plants with the compatible oomycete Hyaloperonospora arabidopsidis isolate Emco5 and the virulent bacterial pathogen $P$. syringae pv. tomato DC3000. We did not observe any clear difference in the growth rate of $P$. syringae pv. tomato DC3000 or the macroscopical infection phenotype of $H$. arabidopsidis Emco5 between wild-type and double mutant plants (Supplementary Fig. 2). We further tested the incompatible oomycete Phythophtora infestans and the necrotrophic fungus Botrytis cinerea isolate 2100. Again, both genotypes did not differ in the outcome of the infection, showing a resistant phenotype (Table 1). Thus, simultaneous knockout of WRKY18 and WRKY4O does not alter resistance or susceptibility towards these pathogens.

In barley, the effector-dependent interaction of MLA10 with $W R K Y$ factors 1 and 2 provides a direct link between basal defense and $R$ protein-mediated resistance (Shen et al. 2007). To test whether wrky 18 wrky 40 plants are impaired in R proteinmediated defense, wild-type and wrky 18 wrky 40 plants were infected with two $P$. syringae pv. tomato strains expressing either the bacterial effector AvrRPMI or AvrRPS4. Interestingly, infection with the avirulent bacterial strain $P$. syringae pv. tomato AvrRPS4 revealed an increased susceptibility of wrky 18 wrky 40 plants, allowing about tenfold more bacterial growth as compared with resistant wild-type plants at 3 dpi (Fig. 5A). In contrast, resistance towards P. syringae pv. tomato AvrRPM1 was not altered in wrky 18 wrky 40 plants (Fig. 5B).

As WRKY40 protein binds to the promoter region of $E D S 1$, it is conceivable that mutations in one or both WRKY18 or WRKY40 affect EDS1 signaling. Therefore, wrkyl8 wrky40 plants were challenged with additional pathogens against which resistance is known to depend on TIR-NB-LRR-type R proteins and functional EDS1. Resistance against $H$. arabidopsidis isolates Emwa1 and Cala2 is mediated by the TIR-NB-LRR R proteins RPP2 and RPP4, respectively, and both are EDS1-dependent (Slusarenko and Schlaich 2003). Infection with these two isolates revealed no phenotypic differences between wild-type and wrky 18 wrky 40 plants (Table 1). Together, this data suggests that increased susceptibility of wrky 18 wrky 40 plants towards $P$. syringae pv. tomato AvrRPS4 is highly specific and is not due to a general breakdown of EDS1 function. To test whether WRKY18 and WRKY40 are specifically involved in the TIRNB-LRR signaling pathway during plant $-P$. syringae pv. tomato interactions, a second avirulent strain, $P$. syringae pv. tomato HopA1, was used for infection of wrky 18 wrky 40 mutant and wild-type plants. Resistance of wild-type Col-0 plants towards $P$. syringae pv. tomato HopA1 is also mediated by a TIR-NBLRR-type R protein and requires functional EDS1 (Kim et al. 2009). However, infections of both genotypes revealed no differences in the macroscopic phenotype and bacterial colonization (Fig. 5C). Thus, wrky18 wrky40 plants reveal a rather specific susceptibility phenotype against $P$. syringae pv. tomato AvrRPS4 infection that was not observed with other tested $P$. syringae pv. tomato strains and, on the other hand, a resistant phenotype against $G$. orontii without exhibiting a broad-spectrum resistance against other powdery mildews.

\section{DISCUSSION}

Previous work on wrky 18 wrky 40 focused on the transcriptional changes occurring during $G$. orontii infection and in identifying gene expression differences between susceptible wild-type and resistant wrkyl8 wrky40 plants (Pandey et al. 2010). In the current work, we performed genetic studies to determine crucial components required for loss-of-WRKY18 WRKY40-mediated G. orontii resistance. Several key findings were obtained.

Firstly, we uncovered an important role of $P A D 3$ for preinvasive but not for postinvasive defense. The wrky 18 wrky 40 pad3 triple mutant exhibited wild-type-like penetration rates but showed a late wrkyl8 wrky40-like resistance phenotype. These data point to an active suppression of camalexin biosynthesis by $G$. orontii in a WRKY18- and WRKY40-dependent manner and an inability of $G$. orontii to degrade or tolerate camalexin as described for other fungi (Glawischnig 2007; Pandey et al. 2010). Notably, uninfected wrky 18 wrky40 plants already accumulate higher camalexin levels than wild-type plants (Pandey et al. 2010). Therefore, deregulation in timing and magnitude of camalexin accumulation may, at least in part, be the molecular basis for the preinvasive resistant phenotype observed in wrky 18 wrky40. Additionally, our data suggest that camalexin-dependent preinvasive fungal restriction can be uncoupled from postinvasive resistance and, thereby, relegating effectiveness of camalexin accumulation to an early antifungal defense. However, host cell-entry restriction during the interaction of $G$. orontii with wrky 18 wrky 40 plants appears to be rather weak. In wrky 18 wrky 40 plants, $60 \%$ of the spores still enter the host tissue, whereas, for example, mlo2 or $m l o 2$ mlo6 mlo12 mutant plants show 30\% and less than 5\% fungal entry success, respectively (Consonni et al. 2006). Thus, this preinvasive host-defense mechanism is insufficient to explain the explicit postinvasive resistance phenotype of wrkyl8 wrky 40 plants observed at later stages of fungal infection.

Secondly, induced expression of the 4MI3G biosynthesis gene $C Y P 81 F 2$ correlated with elevated $4 \mathrm{MI} 3 \mathrm{G}$ levels in wrky 18 wrky40 plants upon $G$. orontii infection and a requirement of $4 \mathrm{MI} 3 \mathrm{G}$ for both pre- and postinvasive defense. Bednarek and colleagues (2009) described the consecutive requirement of various Trp-derived indole-glucosinolates for pre- and postinvasive defense against fungal nonhost pathogens. However, a direct role of $4 \mathrm{MI} 3 \mathrm{G}$ in antifungal defense remains to be demonstrated. 4MI3G itself may have a yet-unknown signaling function required for resistance of the wrky 18 wrky 40 mutant, as it was hypothesized to act as a signaling molecule for MAMP-induced callose formation (Clay et al. 2009). Alternatively, altered 4MI3G levels may influence the level of additional activated compounds, thereby affecting the outcome of the infection. The atypical myrosinase PEN2 was shown to be crucial for $4 \mathrm{MI} 3 \mathrm{G}$ breakdown to an unknown compound and to be essential for pathogen-dependent callose deposition and resistance (Bednarek et al. 2009; Clay et al. 2009). PEN2 and CYP81F2 activities were also shown to be required for effective defense against nonadapted powdery mildews and other fungal pathogens (Bednarek et al. 2009; Maeda et al. 2009). Sanchez-Vallet and colleagues (2010) demonstrated a crucial role of $\mathrm{CYP} 81 \mathrm{~F} 2$ and PEN2 for nonhost resistance against the adapted necrotrophic fungal isolate Plectospharella cucumerina BMM, whereas resistance responses to nonadapted isolates were unaffected in cyp $81 f 2$ and pen 2 mutants. On the other hand, mutations in $C Y P 79 B 1$ and $C Y P 79 B 2$ acting upstream of CYP81F2 and PEN2 in the Trp-derived indoleglucosinolate biosynthesis pathway revealed increased susceptibility also towards nonadapted isolates, strongly suggesting additional PEN2-independent indolic products with antifungal activities (Sanchez-Vallet et al. 2010). As homozygous wrkyl8 wrky 40 pen 2 plants could not be identified, we currently cannot distinguish between the requirement of 4MI3G, its PEN2 breakdown product, or other derivatives for $G$. orontii resistance of wrky 18 wrky 40 mutant plants. 
Thirdly, the PEN1 secretory pathway does not play a vital role in wrky18 wrky40-dependent G. orontii resistance. The membrane-associated syntaxin PEN1 focally accumulates in papillae formed underneath fungal entry sites of adapted and nonadapted powdery mildews but not in papillae triggered by the entry attempts of other ascomycetes (Assaad et al. 2004; Bhat et al. 2005; Meyer et al. 2009; Shimada et al. 2006). The mechanism underlying PEN1-mediated preinvasive resistance appears to be rather specific for nonhost powdery mildews such as B. graminis f. sp. hordei and Erysiphe pisi (Collins et al. 2003; Lipka et al. 2005), which is consistent with our findings that penetration resistance was completely unaffected in wrky 18 wrky 40 penl plants. However, at later infection stages, resistance in wrky 18 wrky40 pen 1 plants was associated with the appearance of large necrotic leaf areas that were absent in resistant wrky 18 wrky 40 plants. Postpenetration resistance is often associated with the appearance of a hypersensitive response at the site of infection. Posthaustorial powdery mildew resistance was shown to depend on a set of genes including EDS1, PAD4, and SAG101 (Lipka et al. 2005; Stein et al. 2006). EDS1 is required for the promotion of leaf cell death, contributes to basal defense and systemic resistance, and was differentially expressed in naive and $G$. orontii-infected wrkyl8 wrky40 plants (Attaran et al. 2009; Pandey et al. 2010; Rusterucci et al. 2001; Vlot et al. 2008). Thus, the appearance of large necrotic areas in wrkyl 8 wrky 40 pen1 plants might be the consequence of an altered basal or systemic defense programs or both.

Fourthly, both EDS1 and the SA signaling pathway, which have been associated with defense against powdery mildew fungi, impact resistance of wrky 18 wrky 40 against G. orontii (Chandran et al. 2009; Dewdney et al. 2000; Lipka et al. 2005; Pandey et al. 2010). Yet, despite a deregulation of EDS1 expression in wrky 18 wrky 40 plants, expression of the crucial SA biosynthesis gene SID2, SA accumulation, and induction of the downstream SA marker gene $P R 1$ did not differ in resistant wrky 18 wrky 40 and susceptible wild-type plants upon $G$. orontii infection. It is noteworthy that $G$. orontii only infects epidermal cells and our expression studies and hormone measurements were performed in whole leaf samples. Thus, it is conceivable that local differences in gene expression or hormone levels between infected and uninfected cells are masked. Nevertheless, activation of SA signaling upon G. orontii is in agreement with earlier reports demonstrating the induction of SA-dependent defense responses in Arabidopsis, with mutants in SA biosynthesis and signaling exhibiting enhanced susceptibility to this fungus (Dewdney et al. 2000; Reuber et al. 1998). In our analyses, the SA signaling pathway is activated after fungal penetration (approximately $48 \mathrm{hpi}$ ) in both genotypes, consistent with previous studies showing that the SA signaling pathway of the host plays a more important role at later infection stages (Chandran et al. 2009; Dewdney et al. 2000; Reuber et al. 1998). However, reconstitution of wild-type-like penetration rates in wrky 18 wrky 40 sid2 plants points to a role of SA also for early penetration resistance in wrky 18 wrky 40 mutant plants. Possibly, SA may influence processes required for penetration resistance in a loss-of-WRKY18 WRKY40-dependent manner. Clearly, the role of SA for preinvasive defense requires further investigation. However, at later infection stages, wrkyl8 wrky 40 sid 2 plants revealed wild-type-like fungal proliferation, demonstrating a crucial role of SA for postinvasive resistance of wrky 18 wrky 40 mutant plants. This is supported by recent studies reporting that SID2 and PAD4 are required for postinvasion resistance in Arabidopsis (Wen et al. 2011). Moreover, as WRKY18 and WRKY40 expression is strongly induced upon exogenous SA treatment (Dong et al. 2003), we hypothesize that processes influenced by loss-of-WRKY18 and WRKY40 act downstream of EDS1 and SA in defense against G. orontii.
In contrast to G. orontii, wrky 18 wrky 40 plants did not show increased resistance against two other tested biotrophic powdery mildews. The wrky 18 wrky 40 mutant does not constitutively express defense-associated genes at high levels, and the absence of broad-spectrum resistance clearly separates wrky 18 wrky 40 dependent $G$. orontii resistance from other powdery mildew resistant mutants (Pandey et al. 2010). Many of these mutants, including, mlo2, mlo2 mlo6 mlo12, pmr4, edrl, or cevl, reveal broad-spectrum resistances against powdery mildews caused by loss of susceptibility factors (Consonni et al. 2006), constitutive defense gene expression (Ellis and Turner 2001; Flors et al. 2008; Nishimura et al. 2003), or altered cell-wall compositions (Ellis et al. 2002; Nishimura et al. 2003; Vogel et al. $2002,2004)$, which in some cases also leads to increased resistance against diverse pathogens. The $e d r l$ and $e d r 2$ mutants exhibit broad-spectrum resistance against powdery mildews without constitutive defense activation but also confer resistance against other pathogens, including $P$. syringae pv. tomato DC3000 (Flors et al. 2008), which was not observed for wrkyl8 wrky40 plants. Strikingly, however, infection of wrky 18 wrky 40 plants with $P$. syringae pv. tomato AvrRPS4 showed clearly increased susceptibility towards this bacterial pathogen. This susceptibility phenotype appears specific to $P$. syringae pv. tomato AvrRPS4, since it was not observed with any other $P$. syringae pv. tomato strain tested. As the wrky 18 wrky $40 \mathrm{mu}-$ tant did not exhibit broad-spectrum resistance against powdery mildews and was not generally impaired in $\mathrm{R}$ protein-mediated resistance, we hypothesize rather specific defense perturbations during G. orontii and $P$. syringae pv. tomato AvrRPS4 infections. It is conceivable that these pathogens differentially affect distinct responses in wrky 18 wrky 40 plants, as both pathogens secrete a substantial repertoire of unique effectors into the plant cell during infection (Lindeberg et al. 2009, 2012; Spanu et al. 2010). Recently direct physical association of the secreted effector AvrRPS4 and the R protein RPS4 with EDS1 in the plant cell nucleus was demonstrated (Heidrich et al. 2011). Moreover, interaction between an $\mathrm{R}$ protein and WRKY transcription factors is the basis for MLA-mediated resistance in barley upon B. graminis f. sp. hordei infection (Shen et al. 2007). We tested but failed to observe interaction of WRKY18 and WRKY40 with full-length RPS4 and truncated versions containing only the $\mathrm{N}$-terminal TIR domain in yeast and in coinfiltration experiments in Nicotiana benthamiana epidermal cells, irrespective of the presence or absence of the cognate effector protein (data not shown). Thus, it remains unclear with which host components WRKY18 and WRKY40 are mechanistically linked for effective defense against $P$. syringae pv. tomato AvrRPS4 or which key genes required for resistance are regulated by these transcription factors.

Future studies will need to address several important aspects related to the negative role of WRKY18 and WRKY40 in $G$. orontii resistance and its positive function in mediating resistance towards $P$. syringae pv. tomato AvrRPS4. Recently, several $G$. orontii-specific secreted effector candidates were identified that interfere with the plant immune response (Spanu et al. 2010; Wessling et al. 2012). Whether WRKY18 or WRKY40 are targets of such effectors needs to be tested. Moreover, a more detailed analysis of altered host secondary metabolites, in particular of glucosinolates, in wrky 18 wrky 40 plants is required. Additionally, by focusing on identifying proteins interacting with WRKY18 and WRKY40 and by pinpointing the in vivo promoter targets of these two transcription factors during the infection with $G$. orontii and $P$. syringae pv. tomato AvrRPS4, we hope to uncover some of the missing components that are essential in determining the distinct outcomes observed in the host. Finally, it is obvious that we must position these transcription factors in the increasingly complex regu- 
latory network, in order to understand how their functions influence, both positively and negatively, host cellular responses.

\section{MATERIALS AND METHODS}

\section{Plant material.}

All experiments were performed using Arabidopsis thaliana Columbia-0 (Col-0) wild-type plants or mutants in the Col-0 background. The wrky 18 wrky 40 mutant published by Pandey and associates (2010) was used for all experiments. Triple mutants were generated by crossing wrky 18 wrky 40 homozygous plants with sid2-1, eds1-2, rrtf1, pad3-1, pen1-1, cyp81f2-1 homozygous plants. Homozygous triple mutants were identified by PCR or via cleaved amplified polymorphic sequences (CAPS) or both and were used for further experiments.

\section{Pathogens.}

Pathogens and their sources are listed in Table 2.

\section{Powdery mildew infections.}

Golovinomyces orontii was propagated on pad4 sag101 double mutant Arabidopsis plants in closed cabinets under shortday conditions (10 h light and $14 \mathrm{~h}$ darkness) at $22^{\circ} \mathrm{C}$ with $70 \%$ humidity. Four-week-old plants were used for infections. All infections were performed by dusting without touching the plants, to avoid wound responses. A brush was used to spread spores over the plant. Infected plants were further kept under short-day conditions. Control samples (0 hpi) were taken before inoculation with the fungus. G. cichoracearum and G. cruciferarum were propagated on their natural host plants, zucchini (Gold rush) and Brassica juncea, respectively, under short-day conditions ( $8 \mathrm{~h}$ light and $16 \mathrm{~h}$ darkness) at $22^{\circ} \mathrm{C}$ with $80 \%$ humidity.

\section{Powdery mildew penetration counts.}

Infected leaf samples were taken $48 \mathrm{hpi}$, and chlorophyll was destained in an EtOH/acetic acid solution (3:1) for at least $24 \mathrm{~h}$. To visualize epiphytic fungal growth, four leaves of one biological replicate (individual plant) of a representative experiment were stained in Coomassie Brilliant Blue solution (45\% $\mathrm{MeOH}, 10 \%$ acetic acid, $0.05 \%$ Coomassie R 250) and were prepared for microscopy. Four biological replicates (individual plants) were analyzed per experiment and each experiment was repeated at least twice. For fungal host cell-entry rates, the ratio of penetrating spores that formed secondary hyphae to all spores that formed an appressorium was calculated. Values represent means \pm standard deviation (SD) of one representative experiment with four individual plants $(n=4)$.

\section{Powdery mildew conidiophore counts.}

For conidiophore counts, at least nine leaves of three individual plants $(n=3)$ were harvested at $7 \mathrm{dpi}$ and were destained in $80 \% \mathrm{EtOH}$ for several days. To visualize fungal structures, destained leaves were stained in $0.6 \%$ Coomassie Brilliant Blue solution (in 100\% EtOH) and were prepared for microscopy. Microscopy was performed using a Leica epiflourescence microscope (Leica GmbH, Wetzlar, Germany). Transmitted light and filter A (BP 340 to 380) was used for conidiophore counting. This was done by determining the number of conidiophores of single sporulated spores at $7 \mathrm{dpi}$.

\section{Pseudomonas syringae infections.}

For Pseudomonas syringae infections, bacteria were plated from glycerol stocks on fresh NYGA (per liter: $5 \mathrm{~g}$ of bactopeptone, $3 \mathrm{~g}$ of yeast extract, $20 \mathrm{ml}$ of glycerol, with $15 \mathrm{~g}$ of agar) agar plates containing the appropriate antibiotics. Bacteria were grown for 2 days at $28^{\circ} \mathrm{C}$, were plated again on fresh NYGA agar plates, and were incubated overnight at $28^{\circ} \mathrm{C}$. Plants were kept under a hood sprayed with water, to increase humidity and induce stomata opening, for $3 \mathrm{~h}$ before infection. Infections were performed as described earlier (Heidrich et al. 2011), repeated at least three times. Values represent means \pm SD of a representative experiment with four individual plants $(n=4)$.

\section{H. arabidopsidis infections.}

A concentration of $4 \times 10^{4}$ spores $/ \mathrm{ml}$ in $\mathrm{H}_{2} \mathrm{O}$ was used for infection of 10-day-old plants. Infected plants were incubated in sealed trays under short-day conditions (10 h light and $14 \mathrm{~h}$ darkness, $22^{\circ} \mathrm{C}, 70 \%$ humidity) for 7 days. Afterwards, 20 to 30 leaves were harvested into $10-\mathrm{ml}$ reaction tubes and were transferred to a 1:1 trypan blue/EtOH solution for staining of oomycete structures. Leaf samples were boiled for $5 \mathrm{~min}$ and trypan blue/EtOH solution was removed and exchanged by chloralhydrate for destaining plant leaves. Afterwards, chloralhydrate was removed and leaves were prepared for transmitted light microscopy. Infections were repeated at least twice with similar results.

\section{Phytophthora infestans infections.}

Phytophthora infections were carried out with two different concentrations. Four-week-old plants were infected with a solution of 500 or 50 spores $/ \mu \mathrm{l}$ in $\mathrm{H}_{2} 0$, and $10 \mu \mathrm{l}$ were used for drop-infection of plant leaves. Leaf samples were harvested 3 days after inoculation and were stained with trypan blue as described by Lipka and associates (2005). After destaining of chlorophyll, leaves infected with high spore concentrations were scanned and trypan blue staining intensities at inoculation sites were determined, using the image processing software ImageJ. Leaves infected with low spore concentrations were investigated by transmitted light microscopy. Infections were repeated twice with similar results.

\section{Botrytis cinerea infections.}

$B$. cinerea (isolate 2100 ) was cultivated on potato dextrose plates for 10 days at $22^{\circ} \mathrm{C}$. Spores were collected from the plate and were washed and stored in $0.8 \% \mathrm{NaCl}$ at a concentration of $10^{7}$ spores $/ \mathrm{ml}$ at $-80^{\circ} \mathrm{C}$ until use. For drop-inoculation of five-week-old Arabidopsis plants, spores were diluted in Vogel buffer (in 1 liter: $15 \mathrm{~g}$ of sucrose, $3 \mathrm{~g}$ of Na-citrate, 5 $\mathrm{g}$ of $\mathrm{K}_{2} \mathrm{HPO}_{4}, 0.2 \mathrm{~g}$ of $\mathrm{MgSO}_{4} 7 \mathrm{H}_{2} \mathrm{O}, 0.1 \mathrm{~g}$ of $\mathrm{CaCl}_{2} 2 \mathrm{H}_{2} \mathrm{O}, 2 \mathrm{~g}$ of $\mathrm{NH}_{4} \mathrm{NO}_{3}$ ) to $5 \times 10^{5}$ spores $/ \mathrm{ml}$. For drop infections, $5 \mu \mathrm{l}$ of diluted spores were applied to single leaves. Mock infections were performed using Vogel buffer. Plants were kept prior to and during the infection under sealed hoods with high humidity. B. cinerea infections were performed by R. Birkenbihl (MPIPZ Cologne, Germany).

\section{Quantitative real-time PCR (qPCR).}

qPCR analyses were performed with cDNA corresponding to approximately $15 \mathrm{ng}$ of RNA before reverse transcription on an iQ5 multicolor real-time PCR detection system using iQ5 SYBR Green Ready Mix (BioRad, Munich). Gene-specific primers were designed with Primer3 software (Rozen and Skaletsky 2000) and were analyzed using NetPrimer (PREMIER Biosoft International, Palo Alto, CA, U.S.A.). Primers were used with a NetPrimer rating of 85 to 100 , as recommended by Czechowski and associates (2005). Expressed gene AT4G26410 was used as reference (Czechowski et al. 2005). qPCR results were analyzed by the $\Delta \Delta \mathrm{C}_{\mathrm{t}}$ method as described earlier (Livak and Schmittgen 2001). Fold changes were calculated relative to wild-type untreated ( $0 \mathrm{hpi}$ ) samples set to 1 . Data are shown as the mean \pm SD from two biological and two technical replicates $(n=2)$. All expression kinetic experiments were repeated at least twice with similar results. 


\section{Hormone measurements.}

Four-week-old plants were used for free SA measurements. Plant leaf material from four individual plants $(200 \mathrm{mg})$ was collected $(n=4)$, was frozen in liquid nitrogen, and was stored at $-80^{\circ} \mathrm{C}$ until use. Frozen tissue was transferred to FastPrep tubes (Qbiogene, Carlsbad, CA, U.S.A.) containing $900 \mathrm{mg}$ of FastPrep lysing matrix and $1 \mathrm{ml}$ of ethyl acetate spiked with $200 \mathrm{ng}$ of D4-SA as internal standards. Samples were homogenized by reciprocal shaking (FastPrep speed 6.5) twice for $45 \mathrm{~s}$ each time and were centrifuged at $13,000 \mathrm{rpm}$ for $20 \mathrm{~min}$ at $4^{\circ} \mathrm{C}$. The supernatant was transferred to fresh $2-\mathrm{ml}$ reaction tubes, and the extraction was repeated once by adding $0.5 \mathrm{ml}$ of ethyl acetate without internal standard to the same tissue, followed by a centrifugation step at 13,000 rpm for $20 \mathrm{~min}$ at $4^{\circ} \mathrm{C}$. Both supernatants were combined and were evaporated, using a vacuum concentrator until dryness at $30^{\circ} \mathrm{C}$. Dried samples were dissolved in $500 \mu \mathrm{l}$ of $70 \% \mathrm{MeOH}$, were mixed for at least $5 \mathrm{~min}$, and were subsequently centrifuged at 13,000 rpm for $10 \mathrm{~min}$. supernatant $(400 \mu \mathrm{l})$ was transferred into fresh high-pressure liquid chromatography (HPLC) vials. Measurements were conducted on a liquid chromatography tandem mass spectrometry system (Varian 1200; Agilent Technologies, Santa Clara, CA, U.S.A.).

\section{Secondary metabolite measurements by HPLC.}

Plant leaf tissue $(200 \mathrm{mg})$ was collected and frozen in liquid nitrogen until use. Dimethyl sulfoxide $(10 \mu \mathrm{l}$ per $4 \mathrm{mg}$ of fresh weight material) and 10 to 30 Zirconia Beads (BioSpec, Bartlesville, OK, U.S.A.) were added to the samples and were homogenized for $30 \mathrm{~s}$ in a BeadBeater (BioSpec). Homogenized samples were centrifuged at $15,000 \mathrm{rpm}$ at $4^{\circ} \mathrm{C}$ for $20 \mathrm{~min}$, and supernatants were transferred to HPLC well plates and used for HPLC analysis on an Agilent 1100 HPLC system equipped with DAD and FLD detectors. The concentration of the metabolites of interest were quantified on the basis of the comparison of their peak areas with those obtained during HPLC analyses of known amounts of the respective compound.

\section{ACKNOWLEDGMENTS}

The excellent technical assistance of E. Logemann was highly appreciated. We thank R. Panstruga (RWTH Aachen, Germany) and R. Birkenbihl (MPIPZ Cologne, Germany) for critical reading of the manuscript and R. Birkenbihl for performing the $B$. cinerea infections. A. Coerdt (MPIPZ Cologne, Germany) kindly provided RPS4 constructs for yeast two-hybrid experiments and coinfiltration studies. P. Bednarek (IBCH Poznań, Poland) supported us with the analysis of secondary metabolite measurements. This work was partly funded by two International Max Planck Research School (IMPRS) fellowships (M. Schön and A. Töller), by the Deutsche Forschungsgemeinschaft (DFG) (C. Roth and M. Wiermer) and DFG SFB670 grant (I. E. Somssich).

\section{LITERATURE CITED}

Aarts, N., Metz, M., Holub, E., Staskawicz, B. J., Daniels, M. J., and Parker, J. E. 1998. Different requirements for EDS1 and NDR1 by disease resistance genes define at least two $R$ gene-mediated signaling pathways in Arabidopsis. Proc. Natl. Acad. Sci. U.S.A. 95:10306-10311.

Assaad, F. F., Qiu, J. L., Youngs, H., Ehrhardt, D., Zimmerli, L., Kalde, M., Wanner, G., Peck, S. C., Edwards, H., Ramonell, K., Somerville, C. R., and Thordal-Christensen, H. 2004. The PEN1 syntaxin defines a novel cellular compartment upon fungal attack and is required for the timely assembly of papillae. Mol. Biol. of the Cell 15:5118-5129.

Attaran, E., Zeier, T. E., Griebel, T., and Zeier, J. 2009. Methyl salicylate production and jasmonate signaling are not essential for systemic acquired resistance in Arabidopsis. Plant Cell 21:954-971.

Bartsch, M., Gobbato, E., Bednarek, P., Debey, S., Schultze, J. L., Bautor, J., and Parker, J. E. 2006. Salicylic acid-independent ENHANCED DISEASE SUSCEPTIBILITY1 signaling in Arabidopsis immunity and cell death is regulated by the monooxygenase FMO1 and the Nudix hydrolase NUDT7. Plant Cell 18:1038-1051.
Bednarek, P., Pislewska-Bednarek, M., Svatos, A., Schneider, B., Doubsky, J., Mansurova, M., Humphry, M., Consonni, C., Panstruga, R., Sanchez-Vallet, A., Molina, A., and Schulze-Lefert, P. 2009. A glucosinolate metabolism pathway in living plant cells mediates broadspectrum antifungal defense. Science 323:101-106.

Bhat, R. A., Miklis, M., Schmelzer, E., Schulze-Lefert, P., and Panstruga, R. 2005. Recruitment and interaction dynamics of plant penetration resistance components in a plasma membrane microdomain. Proc. Natl. Acad. Sci. U.S.A. 102:3135-3140.

Chandran, D., Tai, Y. C., Hather, G., Dewdney, J., Denoux, C., Burgess, D. G., Ausubel, F. M., Speed, T. P., and Wildermuth, M. C. 2009. Temporal global expression data reveal known and novel salicylate-impacted processes and regulators mediating powdery mildew growth and reproduction on Arabidopsis. Plant Physiol. 149:1435-1451.

Chisholm, S. T., Coaker, G., Day, B., and Staskawicz, B. J. 2006. Hostmicrobe interactions: Shaping the evolution of the plant immune response. Cell 124:803-814.

Clay, N. K., Adio, A. M., Denoux, C., Jander, G., and Ausubel, F. M. 2009. Glucosinolate metabolites required for an Arabidopsis innate immune response. Science 323:95-101.

Collins, N. C., Thordal-Christensen, H., Lipka, V., Bau, S., Kombrink, E., Qiu, J. L., Huckelhoven, R., Stein, M., Freialdenhoven, A., Somerville, S. C., and Schulze-Lefert, P. 2003. SNARE-protein-mediated disease resistance at the plant cell wall. Nature 425:973-977.

Consonni, C., Humphry, M. E., Hartmann, H. A., Livaja, M., Durner, J., Westphal, L., Vogel, J., Lipka, V., Kemmerling, B., Schulze-Lefert, P., Somerville, S. C., and Panstruga, R. 2006. Conserved requirement for a plant host cell protein in powdery mildew pathogenesis. Nat. Genet. 38:716-720.

Czechowski, T., Stitt, M., Altmann, T., Udvardi, M. K., and Scheible, W. R. 2005. Genome-wide identification and testing of superior reference genes for transcript normalization in Arabidopsis. Plant Physiol. 139:5-17.

Dewdney, J., Reuber, T. L., Wildermuth, M. C., Devoto, A., Cui, J., Stutius, L. M., Drummond, E. P., and Ausubel, F. M. 2000. Three unique mutants of Arabidopsis identify eds loci required for limiting growth of a biotrophic fungal pathogen. Plant J. 24:205-218.

Dodds, P. N., and Rathjen, J. P. 2010. Plant immunity: Towards an integrated view of plant-pathogen interactions. Nat. Rev. Genet. 11:539548.

Dong, J., Chen, C., and Chen, Z. 2003. Expression profiles of the Arabidopsis WRKY gene superfamily during plant defense response. Plant Mol. Biol. 51:21-37.

Eichmann, R., and Huckelhoven, R. 2008. Accommodation of powdery mildew fungi in intact plant cells. J. Plant Physiol. 165:5-18.

Ellis, C., and Turner, J. G. 2001. The Arabidopsis mutant cev1 has constitutively active jasmonate and ethylene signal pathways and enhanced resistance to pathogens. Plant Cell 13:1025-1033.

Ellis, C., Karafyllidis, I., Wasternack, C., and Turner, J. G. 2002. The Arabidopsis mutant cev1 links cell wall signaling to jasmonate and ethylene responses. Plant Cell 14:1557-1566.

Falk, A., Feys, B. J., Frost, L. N., Jones, J. D., Daniels, M. J., and Parker, J. E. 1999. EDS1, an essential component of R gene-mediated disease resistance in Arabidopsis has homology to eukaryotic lipases. Proc. Natl. Acad. Sci. U.S.A. 96:3292-3297.

Flors, V., Ton, J., van Doorn, R., Jakab, G., Garcia-Agustin, P., and Mauch-Mani, B. 2008. Interplay between JA, SA and ABA signalling during basal and induced resistance against Pseudomonas syringae and Alternaria brassicicola. Plant J. 54:81-92.

Frye, C. A., and Innes, R. W. 1998. An Arabidopsis mutant with enhanced resistance to powdery mildew. Plant Cell 10:947-956.

Glawischnig, E. 2007. Camalexin. Phytochemistry 68:401-406.

Glazebrook, J. 2005. Contrasting mechanisms of defense against biotrophic and necrotrophic pathogens. Annu. Rev. Phytopathol. 43:205227.

Heidrich, K., Wirthmueller, L., Tasset, C., Pouzet, C., Deslandes, L., and Parker, J. E. 2011. Arabidopsis EDS1 connects pathogen effector recognition to cell compartment-specific immune responses. Science 334:14011404

Khandelwal, A., Elvitigala, T., Ghosh, B., and Quatrano, R. S. 2008. Arabidopsis transcriptome reveals control circuits regulating redox homeostasis and the role of an AP2 transcription factor. Plant Physiol. 148:2050-2058.

Kim, S. H., Kwon, S. I., Saha, D., Anyanwu, N.C., and Gassmann, W. 2009. Resistance to the Pseudomonas syringae effector HopA1 is governed by the TIR-NBS-LRR protein RPS6 and is enhanced by mutations in SRFR1. Plant Physiol. 150:1723-1732.

Kwon, C., Neu, C., Pajonk, S., Yun, H. S., Lipka, U., Humphry, M., Bau, S., Straus, M., Kwaaitaal, M., Rampelt, H., El Kasmi, F., Jurgens, G., Parker, J., Panstruga, R., Lipka, V., and Schulze-Lefert, P. 2008. Co-option of a default secretory pathway for plant immune responses. Nature 451:835-840. 
Lindeberg, M., Cunnac, S., and Collmer, A. 2009. The evolution of Pseudomonas syringae host specificity and type III effector repertoires. Mol. Plant Pathol. 10:767-775.

Lindeberg, M., Cunnac, S., and Collmer, A. 2012. Pseudomonas syringae type III effector repertoires: Last words in endless arguments. Trends Microbiol. 20:199-208.

Lipka, U., Fuchs, R., and Lipka, V. 2008. Arabidopsis non-host resistance to powdery mildews. Curr. Opin. Plant Biol. 11:404-411.

Lipka, V., Dittgen, J., Bednarek, P., Bhat, R., Wiermer, M., Stein, M., Landtag, J., Brandt, W., Rosahl, S., Scheel, D., Llorente, F., Molina, A., Parker, J., Somerville, S., and Schulze-Lefert, P. 2005. Pre- and postinvasion defenses both contribute to nonhost resistance in Arabidopsis. Science 310:1180-1183.

Livak, K. J., and Schmittgen, T. D. 2001. Analysis of relative gene expression data using real-time quantitative PCR and the 2(-Delta Delta C(T)) Method. Methods 25:402-408.

Maeda, K., Houjyou, Y., Komatsu, T., Hori, H., Kodaira, T., and Ishikawa, A. 2009. AGB1 and PMR5 contribute to PEN2-mediated preinvasion resistance to Magnaporthe oryzae in Arabidopsis thaliana. Mol. PlantMicrobe Interact. 22:1331-1340.

Maekawa, T., Kufer, T. A., and Schulze-Lefert, P. 2011. NLR functions in plant and animal immune systems: So far and yet so close. Nat. Immunol. 12:817-826.

Meyer, D., Pajonk, S., Micali, C., O'Connell, R., and Schulze-Lefert, P. 2009. Extracellular transport and integration of plant secretory proteins into pathogen-induced cell wall compartments. Plant J. 57:986-999.

Moreau, M., Degrave, A., Vedel, R., Bitton, F., Patrit, O., Renou, J.-P., Barny, M.-A., and Fagard, M. 2012. EDS1 contributes to nonhost resistance of Arabidopsis thaliana against Erwinia amylovora. Mol. Plant-Microbe Interact. 25:421-430.

Nishimura, M. T., Stein, M., Hou, B. H., Vogel, J. P., Edwards, H., and Somerville, S. C. 2003. Loss of a callose synthase results in salicylic acid-dependent disease resistance. Science 301:969-972.

Pandey, S. P., Roccaro, M., Schon, M., Logemann, E., and Somssich, I. E. 2010. Transcriptional reprogramming regulated by WRKY18 and WRKY40 facilitates powdery mildew infection of Arabidopsis. Plant J. 64:912-923.

Parker, J. E., Holub, E. B., Frost, L. N., Falk, A., Gunn, N. D., and Daniels, M. J. 1996. Characterization of eds1, a mutation in Arabidopsis suppressing resistance to Peronospora parasitica specified by several different RPP genes. Plant Cell 8:2033-2046.

Reuber, T. L., Plotnikova, J. M., Dewdney, J., Rogers, E. E., Wood, W. and Ausubel, F. M. 1998. Correlation of defense gene induction defects with powdery mildew susceptibility in Arabidopsis enhanced disease susceptibility mutants. Plant J. 16:473-485.

Rozen, S., and Skaletsky, H. 2000. Primer3 on the WWW for general users and for biologist programmers. Methods Mol. Biol. 132:365-386.

Rusterucci, C., Aviv, D. H., Holt, B. F., 3rd, Dangl, J. L., and Parker, J. E. 2001. The disease resistance signaling components EDS1 and PAD4 are essential regulators of the cell death pathway controlled by LSD1 in Arabidopsis. Plant Cell 13:2211-2224.

Sanchez-Vallet, A., Ramos, B., Bednarek, P., Lopez, G., PislewskaBednarek, M., Schulze-Lefert, P., and Molina, A. 2010. Tryptophanderived secondary metabolites in Arabidopsis thaliana confer non-host resistance to necrotrophic Plectosphaerella cucumerina fungi. Plant J. 63:115-127.

Schlaeppi, K., and Mauch, F. 2010. Indolic secondary metabolites protect Arabidopsis from the oomycete pathogen Phytophthora brassicae. Plant Signal. Behav. 5:1099-1101.

Schlaeppi, K., Abou-Mansour, E., Buchala, A., and Mauch, F. 2010. Disease resistance of Arabidopsis to Phytophthora brassicae is established by the sequential action of indole glucosinolates and camalexin. Plant J. 62:840-851

Shen, Q. H., Saijo, Y., Mauch, S., Biskup, C., Bieri, S., Keller, B., Seki, H. Ulker, B., Somssich, I. E., and Schulze-Lefert, P. 2007. Nuclear activity of MLA immune receptors links isolate-specific and basal diseaseresistance responses. Science 315:1098-1103.

Shimada, C., Lipka, V., O’Connell, R., Okuno, T., Schulze-Lefert, P., and Takano, Y. 2006. Nonhost resistance in Arabidopsis-Colletotrichum interactions acts at the cell periphery and requires actin filament function. Mol. Plant-Microbe Interact. 19:270-279.

Slusarenko, A. J., and Schlaich, N. L. 2003. Downy mildew of Arabidopsis thaliana caused by Hyaloperonospora parasitica (formerly Peronospora parasitica). Mol. Plant Pathol. 4:159-170.

Spanu, P. D., Abbott, J. C., Amselem, J., Burgis, T. A., Soanes, D. M., Stuber, K., Ver Loren van Themaat, E., Brown, J. K., Butcher, S. A. Gurr, S. J., Lebrun, M. H., Ridout, C. J., Schulze-Lefert, P., Talbot, N. J., Ahmadinejad, N., Ametz, C., Barton, G. R., Benjdia, M., Bidzinski, P., Bindschedler, L. V., Both, M., Brewer, M. T., Cadle-Davidson, L., Cadle-Davidson, M. M., Collemare, J., Cramer, R., Frenkel, O., Godfrey, D., Harriman, J., Hoede, C., King, B. C., Klages, S., Kleemann, J., Knoll, D., Koti, P. S., Kreplak, J., Lopez-Ruiz, F. J., Lu, X., Maekawa, T., Mahanil, S., Micali, C., Milgroom, M. G., Montana, G., Noir, S., O’Connell, R. J., Oberhaensli, S., Parlange, F., Pedersen, C., Quesneville, H., Reinhardt, R., Rott, M., Sacristan, S., Schmidt, S. M., Schon, M., Skamnioti, P., Sommer, H., Stephens, A., Takahara, H., Thordal-Christensen, H., Vigouroux, M., Wessling, R., Wicker, T., and Panstruga, R. 2010. Genome expansion and gene loss in powdery mildew fungi reveal tradeoffs in extreme parasitism. Science 330:15431546

Stein, M., Dittgen, J., Sanchez-Rodriguez, C., Hou, B. H., Molina, A., Schulze-Lefert, P., Lipka, V., and Somerville, S. 2006. Arabidopsis PEN3/PDR8, an ATP binding cassette transporter, contributes to nonhost resistance to inappropriate pathogens that enter by direct penetration. Plant Cell 18:731-746.

Vlot, A. C., Klessig, D. F., and Park, S. W. 2008. Systemic acquired resistance: The elusive signal(s). Curr. Opin. Plant Biol. 11:436-442.

Vogel, J., and Somerville, S. 2000. Isolation and characterization of powdery mildew-resistant Arabidopsis mutants. Proc. Natl. Acad. Sci. U.S.A. 97:1897-1902.

Vogel, J. P., Raab, T. K., Schiff, C., and Somerville, S. C. 2002. PMR6, pectate lyase-like gene required for powdery mildew susceptibility in Arabidopsis. Plant Cell 14:2095-2106.

Vogel, J. P., Raab, T. K., Somerville, C. R., and Somerville, S. C. 2004. Mutations in PMR5 result in powdery mildew resistance and altered cell wall composition. Plant J. 40:968-978.

Wen, Y., Wang, W., Feng, J., Luo, M. C., Tsuda, K., Katagiri, F., Bauchan, G., and Xiao, S. 2011. Identification and utilization of a sow thistle powdery mildew as a poorly adapted pathogen to dissect post-invasion non-host resistance mechanisms in Arabidopsis. J. Exp. Bot. 62:21172129

Wessling, R., Schmidt, S. M., Micali, C. O., Knaust, F., Reinhardt, R., Neumann, U., Ver Loren van Themaat, E., and Panstruga, R. 2012. Transcriptome analysis of enriched Golovinomyces orontii haustoria by deep 454 pyrosequencing. Fungal Genet. Biol. 49:470-482.

Wiermer, M., Feys, B. J., and Parker, J. E. 2005. Plant immunity: The EDS1 regulatory node. Curr. Opin. Plant Biol. 8:383-389.

\section{AUTHOR-RECOMMENDED INTERNET RESOURCE}

ImageJ software: rsbweb.nih.gov/ij 